\title{
HMGA2 Gene rs8756 A>C Polymorphism Reduces Neuroblastoma Risk in Chinese Children: A Four-Center Case-Control Study
}

This article was published in the following Dove Press journal: OncoTargets and Therapy

Jiabin Liu, ${ }^{1, *}$ Rui-Xi Hua, (D) ${ }^{1,2, *}$ Yun Cheng, ${ }^{3, *}$ Jinhong Zhu, ${ }^{1,4}$ Jiao Zhang, ${ }^{5}$ Jiwen Cheng, ${ }^{6}$ Haixia Zhou, (iD) ${ }^{7}$ Huimin Xia,' Jun Bian, ${ }^{8}$ Jing $\mathrm{He}$ (iD)

'Department of Pediatric Surgery, Guangzhou Institute of Pediatrics, Guangdong Provincial Key Laboratory of Research in Structural Birth Defect Disease, Guangzhou Women and Children's Medical Center, Guangzhou Medical University, Guangzhou 510623, Guangdong, People's Republic of China; ${ }^{2}$ Department of Oncology, The First Affiliated Hospital of Sun Yat-Sen University, Guangzhou 510080, Guangdong, People's Republic of China; ${ }^{3}$ Department of Gynecology, Nanjing First Hospital Affiliated to Nanjing Medical University, Nanjing 210006, Jiangsu, People's Republic of

China; ${ }^{4}$ Department of Clinical Laboratory,

Biobank, Harbin Medical University Cancer Hospital, Harbin 150040, Heilongjiang, People's Republic of China; ${ }^{5}$ Department of Pediatric Surgery, The First Affiliated Hospital of

Zhengzhou University, Zhengzhou 450052, Henan, People's Republic of China; ${ }^{6}$ Department of Pediatric Surgery, The Second Affiliated Hospital of Xi'an Jiaotong University, Xi'an 710004, Shaanxi, People's Republic of China; ${ }^{7}$ Department of Hematology, The Second Affiliated Hospital and Yuying Children's Hospital of Wenzhou Medical University, Wenzhou 325027, Zhejiang, People's Republic of China;

${ }^{8}$ Department of General Surgery, Xi'an Children's Hospital, Xi'an Jiaotong University Affiliated Children's Hospital, Xi'an 710003, Shaanxi, People's Republic of China

*These authors contributed equally to this work

Correspondence: Jing $\mathrm{He}$

Department of Pediatric Surgery, Guangzhou Institute of Pediatrics, Guangdong Provincial

Key Laboratory of Research in Structural Birth

Defect Disease, Guangzhou Women and

Children's Medical Center, Guangzhou Medical

University, 9 Jinsui Road, Guangzhou 5 I 0623.

Guangdong, People's Republic of China

$\mathrm{Tel} / \mathrm{Fax}+86-2038076560$

Email hejing198374@gmail.com

Jun Bian

Department of General Surgery, Xi'an Children's Hospital, Xi'an Jiaotong University Affiliated

Children's Hospital, 69 Xiju Court Lane, Xi'an

710003 , Shaanxi, People's Republic of China

$\mathrm{Tel} / \mathrm{Fax}+86-2987692108$

Email blandbird@126.com
Background: Neuroblastoma, mainly affecting children, is a lethal malignancy arising from the developing sympathetic nervous system. The genetic etiology of neuroblastoma remains mostly obscure. High mobility group AT-hook 2 (HMGA2), an oncogenic gene, is up-regulated in many tumors. Single nucleotide polymorphisms (SNPs) often modify cancer susceptibility. However, no studies are investigating the association between HMGA2 SNPs and neuroblastoma susceptibility. Methods: We conducted a four-center case-control study to evaluate the association between three HMGA2 polymorphisms (rs6581658 A>G, rs8756 A>C and rs968697 T>C) and neuroblastoma susceptibility in a Chinese population with 505 cases and 1070 controls. Logistic regression was performed to evaluate the strength of the association.

Results: We found that the $\mathrm{rs} 8756 \mathrm{AC} / \mathrm{CC}$ genotypes were associated with a reduced neuroblastoma risk when compared to rs8756 AA genotype [Adjusted odds ratio (OR) $=0.74,95 \%$ confidence interval $(\mathrm{CI})=0.56-0.99, P=0.039]$. Carriers with 3 protective genotypes have lower neuroblastoma susceptibility than those without or with $0-2$ protective genotypes. The stratified analysis revealed that the protective effects of rs8756 AC/CC genotypes were more predominant among children of age $>18$ months, males, and subgroups with the tumor in the mediastinum. Furthermore, haplotype analysis uncovered that haplotype ACC significantly reduced neuroblastoma risk.

Conclusion: Our study indicated $H M G A 2$ rs8756 $\mathrm{A}>\mathrm{C}$ polymorphism is significantly associated with decreased neuroblastoma risk.

Keywords: neuroblastoma, susceptibility, $H M G A 2$, polymorphism

\section{Introduction}

Neuroblastoma is one of the most common pediatric extracranial solid tumors, which is derived from primordial sympathetic neural precursors. ${ }^{1}$ The incidence of neuroblastoma is approximately $1 / 7000$ in the $\mathrm{USA}^{2}$ and $1 / 13,000$ in China. ${ }^{3,4}$ It is the third leading cause of tumor-related death in children, account for $15 \%$ of all cases. ${ }^{5,6}$ Neuroblastoma is a highly heterogeneous disorder characterized by diverse clinical symptoms. For instance, most of the low-risk patients have spontaneous regression without chemotherapy. ${ }^{7}$ However, high- risk patients, constituting near $50 \%$ of neuroblastoma, have widely disseminated disease at diagnosis and have survival rates of less than $40 \%$ despite intensive therapies. ${ }^{8}$ Moreover, the lifelong serious co-existing health issues often affect survivors' social life, including marriage and employment. ${ }^{9}$ Therefore, neuroblastoma remains a great burden for affected families and public health. ${ }^{10}$ 
The pathogenesis of neuroblastoma is not fully understood. Approximately $1-2 \%$ of neuroblastoma cases are familial, ${ }^{11}$ which was reported to associate with the mutation of $P H O X 2 B^{12}$ and $A L K^{13}$ genes. Sporadic neuroblastoma is the primary form of neuroblastoma. Environmental factors such as radiation sources, wood dust, and hydrocarbons ${ }^{14,15}$ have been thought to predispose individuals to neuroblastoma. However, not all offsprings of exposed parents develop neuroblastoma. ${ }^{16}$ It suggests that genetic factors may play a role in the occurrence of neuroblastoma. Increasing evidence indicates that the genetic polymorphisms may somehow contribute to the neuroblastoma susceptibility. ${ }^{17-19}$

Genome-wide association study (GWAS) has shed more light on the genetic etiology of human diseases including cancers. ${ }^{20}$ It now is a powerful tool to study the genetic mechanisms of neuroblastoma. To date, six neuroblastoma GWASs have been performed and several inherited common variants in susceptibility genes were identified. CASC 15 was the first variant discovered to predispose to neuroblastoma by Maris et al in 2008. ${ }^{21}$ Later on, the same group found that several common variants in BARD1 gene $\mathrm{e}^{22}$ were related to high-risk neuroblastoma; moreover, the polymorphisms within DUSP12, DDX4, IL31RA, and HSD17B12 contributed to the low-risk neuroblastoma. ${ }^{23}$ In 2011, Wang et al demonstrated that single nucleotide polymorphisms (SNPs) in the LMO1 gene could modify the neuroblastoma susceptibility. ${ }^{24}$ Diskin et al indicated that the polymorphisms in LIN28B and HACE1 genes also altered susceptibility to neuroblastoma. ${ }^{25}$ More recent GWAS performed by McDaniel et al revealed that common variants within the $C P Z$ gene at $4 \mathrm{p} 16$ and upstream of the $M L F 1$ gene at $3 \mathrm{q} 25$ could modify neuroblastoma susceptibility. ${ }^{26}$ More importantly, the GWAS results are very useful in discovering novel biological processes underlying the malignant transformation of neuroblastoma. For example, Cimmino et al performed a fine-mapping analysis of BARD1 locus (2q35) using GWAS data from 556 high-risk neuroblastoma patients and 2575 controls of European-American ancestry recently. They identified a potentially causative SNP rs $17489363 \mathrm{C}>\mathrm{T}$ in the canonical promoter region that associated with high-risk neuroblastoma. They demonstrated that the risk allele $\mathrm{T}$ of rs 17489363 altered binding sites of the transcription factor $H S F 1$ and lead to low expression of full-length BARD1 mRNA and protein, and the decreased expression of fulllength BARD1 might contribute to neuroblastoma progression through promoting cell proliferation and invasion, the full-length $B A R D 1$ may function as a tumor suppressor. ${ }^{27}$
Furthermore, candidate gene approaches also discovered $N E F L^{18}$ and $C D K N 1 B^{28}$ gene polymorphisms could influence neuroblastoma susceptibility.

Epithelial-to-mesenchymal transition (EMT) is a critical step in the progression of cancer. ${ }^{29}$ EMT confers cancer cells specific mesenchymal characteristics, such as increased cell motility, resistance to apoptosis, and resistance to therapy. ${ }^{30}$ The high mobility group AT-hook 2 (HMGA2), located in chromosome 12q13-15, has been involved in the EMT. ${ }^{31,32}$ The HMGA2 is a member of the high motility group (HMG) protein family and abundantly expressed in the undifferentiated mesenchymal tissues. ${ }^{33}$ One AT-hook basic domain in $H M G A 2$ binds to DNA minor groove at sequences abundant with A and T nucleotides, which helps to install transcriptional or enhancer complexes on chromatin. ${ }^{34}$ Furthermore, HMGA2 functions as a transcription co-regulator by recruiting other transcription-associated proteins. ${ }^{35}$ Apart from EMT, HMGA2 also regulates cell proliferation and differentiation, overexpression of which is observed in numerous human tumor tissues. Sarhadi et al reported that intense $H M G A 2$ expression contributed to the metastasis and poor prognosis in lung cancer. ${ }^{36}$ Elevated HMGA2 expression promoted metastasis and drug resistance in gastrointestinal tumors. ${ }^{37,38} \mathrm{Up}$ regulation of $H M G A 2$ often results from genetic alterations such as gene amplification and translocation. Besides, previous researches showed that some SNPs in genes are able to influence the gene expression and protein structure. There are some studies to evaluate the association between SNPs in the HMGA2 gene and complex human diseases, such as childhood and adult height, ${ }^{39}$ bone mineral density, ${ }^{40}$ and nephropathy. ${ }^{41}$ However, there are no publications regarding the association between $H M G A 2$ gene polymorphisms and cancer susceptibility, including neuroblastoma. Therefore, we performed this four-center case-control study to evaluate the association between SNPs in the HMGA2 gene and neuroblastoma susceptibility in Chinese children.

\section{Materials and Methods Study Subjects}

In total, the current study included 505 clinically and histopathologically diagnosed neuroblastoma cases and 1070 cancer-free controls. ${ }^{42}$ As described previously, participants were recruited from four centers of China: Guangzhou Women and Children's Medical Center, The First Affiliated Hospital of Zhengzhou University, The Second Affiliated Hospital, and Yuying Children's Hospital of Wenzhou Medical University, and the Second Affiliated 
Hospital of Xi' an Jiaotong University. The eligibility criteria for the included subjects were described previously. ${ }^{43}$ Written informed consent was acquired before the study from all participants or their parents. And the study protocols were ratified by the Institutional Review Board of each participating institution. This study was conducted in accordance with the Declaration of Helsinki.

\section{Polymorphism Selection and Genotyping}

We searched for potentially functional $H M G A 2$ polymorphisms in the dbSNP database (https://www.ncbi.nlm.nih.gov/ $\underline{\text { snp/) }}$ and SNPinfo (https://snpinfo.niehs.nih.gov/snpinfo/ snpfunc.html) using the selection criteria described in the previous publication. ${ }^{44}$ Three polymorphisms in the HMGA2 gene were ultimately selected. The rs $8756 \mathrm{~A}>\mathrm{C}$, located in $3^{\prime}$ untranslated region (UTR) of the $H M G A 2$ gene, may affect the microRNA binding affinity, and thereby influence the expression and stabilization of the HMGA2 gene. The rs6581658 $\mathrm{A}>\mathrm{G}$ and rs968697 $\mathrm{T}>\mathrm{C}$, located in the $5^{\prime}$ near gene region, may affect the binding of transcription factors and the transcription of the HMGA2 gene. As showed in Supplemental Figure 1, there was no significant linkage disequilibrium $\left(\mathrm{R}^{2}<0.8\right)$ among these three included SNPs $\left(\mathrm{R}^{2}=0.001\right.$ between rs6581658 and rs968697; $\mathrm{R}^{2}=0.008$ between rs6581658 and rs8756; $\mathrm{R}^{2}=0.001$ between rs968697 and rs8756).

For genotyping, the genomic DNA was purified from venous blood of participants by a TIANamp Blood DNA Kit (TianGen Biotech Co. Ltd., Beijing, China) and genotyped following the standard TaqMan real-time PCR methods. ${ }^{44-46}$ To assure the authenticity of the result, $10 \%$ of the samples were selected randomly to perform a second-time analysis. All repeated samples obtained a $100 \%$ concordance.

\section{Statistical Analysis}

Whether the selected polymorphisms were in HardyWeinberg equilibrium (HWE) in all control was assessed by the goodness-of-fit $\chi^{2}$ test. And the distributions of demographics and allele frequencies between all cases and controls were compared through a two-sided chi-square test. A logistic regression analysis was conducted. Odds ratios (ORs) and 95\% confidence intervals (CIs) were used to evaluate the association between the $H M G A 2$ polymorphisms and neuroblastoma risk. Moreover, stratified analysis was also carried out regarding age, gender, tumor origin site, and clinical stage. All statistical analyses were conducted using SAS software (version 9.4 SAS Institute, NC, USA). And a result was thought to be statistically significant when the $P$ value $<0.05$.

\section{Results}

Associations Between HMGA2 Polymorphisms and Neuroblastoma Risk In the current case-control study, 505 cases and 1070 controls were successfully genotyped (Supplemental Table 1). The genotype frequencies distribution of three selected SNPs were in accordance with HWE among the controls $(P=0.365$ for rs6581658 $\mathrm{A}>\mathrm{G}, P=0.811$ for $\mathrm{rs} 8756 \mathrm{~A}>\mathrm{C}$ and $P=0.780$ for rs968697 $\mathrm{T}>\mathrm{C}$ ). The genotype frequencies of the SNPs in neuroblastoma cases and cancer-free controls were shown in Table 1. In single locus analysis, the rs8756 A $>\mathrm{C}$ was associated with decreased neuroblastoma susceptibility; carriers with rs8756 AC/CC genotypes had significantly reduced neuroblastoma risk when compared with subjects with AA genotype [Adjusted OR $\quad(\mathrm{AOR})=0.74, \quad 95 \% \quad \mathrm{CI}=0.56-0.99$, $P=0.039]$. We further evaluated the combined effect of protective genotypes of $H M G A 2$ on neuroblastoma risk. The results showed that individuals carrying 3 protective genotypes were at significantly lower risk of developing neuroblastoma than those without protective genotypes $\quad(\mathrm{AOR}=0.33,95 \%$ $\mathrm{CI}=0.13-0.84, P=0.020)$ and those with $0-2$ protective genotypes $(\mathrm{AOR}=0.35,95 \% \mathrm{CI}=0.18-0.70, P=0.003)$.

\section{Stratification Analysis}

We investigated the effects of $\mathrm{rs} 8756 \mathrm{~A}>\mathrm{C}$ polymorphism and combined protective genotypes on the neuroblastoma risk among different subgroups defined by age, gender, site of tumor origin, and clinical stage. As shown in Table 2, the rs8756 AC/CC genotypes were significantly associated with decreased neuroblastoma risk in children older than 18 months $(\mathrm{AOR}=0.65,95 \% \mathrm{CI}=0.45-0.93, P=0.020)$, male $(\mathrm{AOR}=0.63$, $95 \% \mathrm{CI}=0.43-0.91, P=0.014)$ and those with tumor of mediastinum origin $(\mathrm{AOR}=0.58,95 \% \mathrm{CI}=0.34-0.99, P=0.044)$. When the protective genotypes were combined, we observed that subjects harboring 3 protective genotypes had a significant lower neuroblastoma risk than those with 0-2 protective genotypes among the following subgroup: age $>18$ months $(\mathrm{AOR}=0.33,95 \% \mathrm{CI}=0.14-0.78, P=0.012)$, male ( $\mathrm{AOR}=0.18,95 \% \mathrm{CI}=0.06-0.60, P=0.005)$, tumor of adrenal gland-origin $(\mathrm{AOR}=0.31,95 \% \mathrm{CI}=0.09-0.99, P=0.048)$ and early-stage tumor $(\mathrm{AOR}=0.28,95 \% \mathrm{CI}=0.10-0.79, P=0.016)$.

\section{HMGA2 Haplotypes and Neuroblastoma Risk}

As shown in Table 3, eight haplotypes were observed in the studied subjects. In comparison with the reference haplotype GAT, a significant association was observed 
Table I Association Between HMGA2 Gene Polymorphisms and Neuroblastoma Risk

\begin{tabular}{|c|c|c|c|c|c|c|c|}
\hline Genotype & $\begin{array}{l}\text { Cases } \\
(\mathrm{N}=505)\end{array}$ & $\begin{array}{l}\text { Controls } \\
(\mathrm{N}=1070)\end{array}$ & $P^{a}$ & $\begin{array}{l}\text { Crude OR } \\
(95 \% \mathrm{Cl})\end{array}$ & $P$ & $\begin{array}{l}\text { Adjusted OR } \\
(95 \% \mathrm{Cl})^{\mathrm{b}}\end{array}$ & $P^{b}$ \\
\hline \multicolumn{8}{|l|}{$\mathrm{rs} 6581658 \mathrm{~A}>\mathrm{G}(\mathrm{HWE}=0.365)$} \\
\hline AA & $319(63.17)$ & $666(62.24)$ & & 1.00 & & 1.00 & \\
\hline AG & $158(3 \mid .29)$ & $350(32.7 I)$ & & $0.98(0.80-1.21)$ & 0.860 & $0.98(0.79-1.21)$ & 0.839 \\
\hline GG & $28(5.54)$ & $54(5.05)$ & & $1.13(0.7 \mathrm{I}-1.80)$ & 0.615 & $1.12(0.7 \mid-1.79)$ & 0.622 \\
\hline Additive & & & 0.893 & $0.99(0.83-1.18)$ & 0.894 & $0.99(0.83-1.18)$ & 0.899 \\
\hline Dominant & $186(36.83)$ & $404(37.76)$ & 0.723 & $0.96(0.77-1.20)$ & 0.724 & $0.96(0.77-1.20)$ & 0.729 \\
\hline Recessive & $477(94.46)$ & $1016(94.95)$ & 0.678 & $1.10(0.69-1.77)$ & 0.678 & $1.11(0.69-1.77)$ & 0.676 \\
\hline \multicolumn{8}{|l|}{$\mathrm{rs} 8756 \mathrm{~A}>\mathrm{C}(\mathrm{HWE}=0.8 \mathrm{II})$} \\
\hline AA & $425(84.16)$ & $854(79.81)$ & & 1.00 & & 1.00 & \\
\hline$A C$ & $76(15.05)$ & $203(18.97)$ & & $0.79(0.60-1.05)$ & 0.100 & $0.79(0.60-1.04)$ & 0.093 \\
\hline $\mathrm{CC}$ & $4(0.79)$ & $13(1.21)$ & & $0.65(0.21-2.00)$ & 0.454 & $0.64(0.21-1.98)$ & 0.439 \\
\hline Additive & & & 0.038 & $0.76(0.58-0.99)$ & 0.038 & $0.76(0.58-0.99)$ & 0.038 \\
\hline Dominant & $80(15.84)$ & $216(20.19)$ & 0.039 & $0.74(0.56-0.99)$ & 0.040 & $0.74(0.56-0.99)$ & 0.039 \\
\hline Recessive & $50 \mathrm{I}(99.2 \mathrm{I})$ & 1057 (98.79) & 0.448 & $0.65(0.21-2.00)$ & 0.452 & $0.65(0.21-1.99)$ & 0.447 \\
\hline \multicolumn{8}{|l|}{ rs968697 T>C $(H W E=0.780)$} \\
\hline $\mathrm{TT}$ & $390(77.23)$ & $799(74.67)$ & & 1.00 & & 1.00 & \\
\hline $\mathrm{TC}$ & $107(21.19)$ & $250(23.36)$ & & $0.92(0.72-1.17)$ & 0.488 & $0.92(0.72-1.17)$ & 0.474 \\
\hline $\mathrm{CC}$ & $8(1.58)$ & $21(1.96)$ & & $0.82(0.36-1.85)$ & 0.628 & $0.84(0.37-1.90)$ & 0.666 \\
\hline Additive & & & 0.258 & $0.88(0.70-1.10)$ & 0.259 & $0.88(0.70-1.10)$ & 0.266 \\
\hline Dominant & 115 (22.77) & $27 \mid(25.33)$ & 0.271 & $0.87(0.68-1.12)$ & 0.272 & $0.87(0.68-1.12)$ & 0.276 \\
\hline Recessive & $497(98.42)$ & $1049(98.04)$ & 0.602 & $0.80(0.35-1.83)$ & 0.603 & $0.81(0.36-1.85)$ & 0.622 \\
\hline \multicolumn{8}{|l|}{$\begin{array}{l}\text { Combined effect of protective } \\
\text { genotypes }^{c}\end{array}$} \\
\hline 0 & $14(2.77)$ & $27(2.52)$ & & 1.00 & & 1.00 & \\
\hline 1 & $320(63.37)$ & $64 I(59.91)$ & & $0.96(0.50-1.86)$ & 0.910 & $0.96(0.50-1.86)$ & 0.901 \\
\hline 2 & 161 (31.88) & $344(32.15)$ & & $0.90(0.46-1.77)$ & 0.765 & $0.90(0.46-1.77)$ & 0.763 \\
\hline 3 & $10(1.98)$ & $58(5.42)$ & & $0.33(0.13-0.84)$ & 0.021 & $0.33(0.13-0.84)$ & 0.020 \\
\hline $0-2$ & 495 (98.02) & $1012(94.58)$ & & 1.00 & & 1.00 & \\
\hline 3 & $10(1.98)$ & $58(5.42)$ & 0.002 & $0.35(0.18-0.70)$ & 0.003 & $0.35(0.18-0.70)$ & 0.003 \\
\hline
\end{tabular}

Notes: The results were in bold, if the $95 \% \mathrm{Cl}$ excluded I or $P<0.05$. ${ }^{a} \chi^{2}$ test for genotype distributions between neuroblastoma patients and cancer-free controls. ${ }^{\mathrm{b}}$ Adjusted for age and gender. ${ }^{\mathrm{C}}$ Risk genotypes were rs658I658 AA/AG, rs8756 AC/CC and rs968697 TC/CC

Abbreviations: $\mathrm{OR}$, odds ratio; $\mathrm{Cl}$, confidence interval; HWE, Hardy-Weinberg equilibrium.

for the haplotype ACC $(\mathrm{AOR}=0.36,95 \% \mathrm{CI}=0.18-0.72$, $P=0.004$ ).

\section{Discussion}

We conducted this four-center case-control study to investigate the association between HMGA2 gene polymorphisms and neuroblastoma susceptibility. Here, we found that rs8756 AC/CC genotypes could reduce the risk of neuroblastoma, especially among subgroups with age $>18$ months, male, and subjects with the mediastinum-origin tumor. To the best of our knowledge, the current study is the first investigation to explore the association between $H M G A 2$ polymorphisms and neuroblastoma risk in the Chinese population.
$H M G A 2$, as one of the major nonhistone chromosomal proteins, has been implicated in many fundamental cellular processes, including gene regulation, cell cycle, differentiation, and viral integration. ${ }^{47}$ This chromatin-associated protein binds to AT-rich DNA sequences and potentiates the effects of transcription factors by altering local chromatin structure. Monzen et al demonstrate that HMGA2 cooperated with the Smad transcription factor to induce the expression of $N k x 2.5$, which encodes an important early transcription factor for cardiac development. This is accomplished through $H M G A 2$ 's binding to the conserved AT-rich region in the $N k \times 2.5$ promoter. The knockdown of $H M G A 2$ blocks cardiomyocyte differentiation in an embryonal carcinoma cell line and completely abrogates 


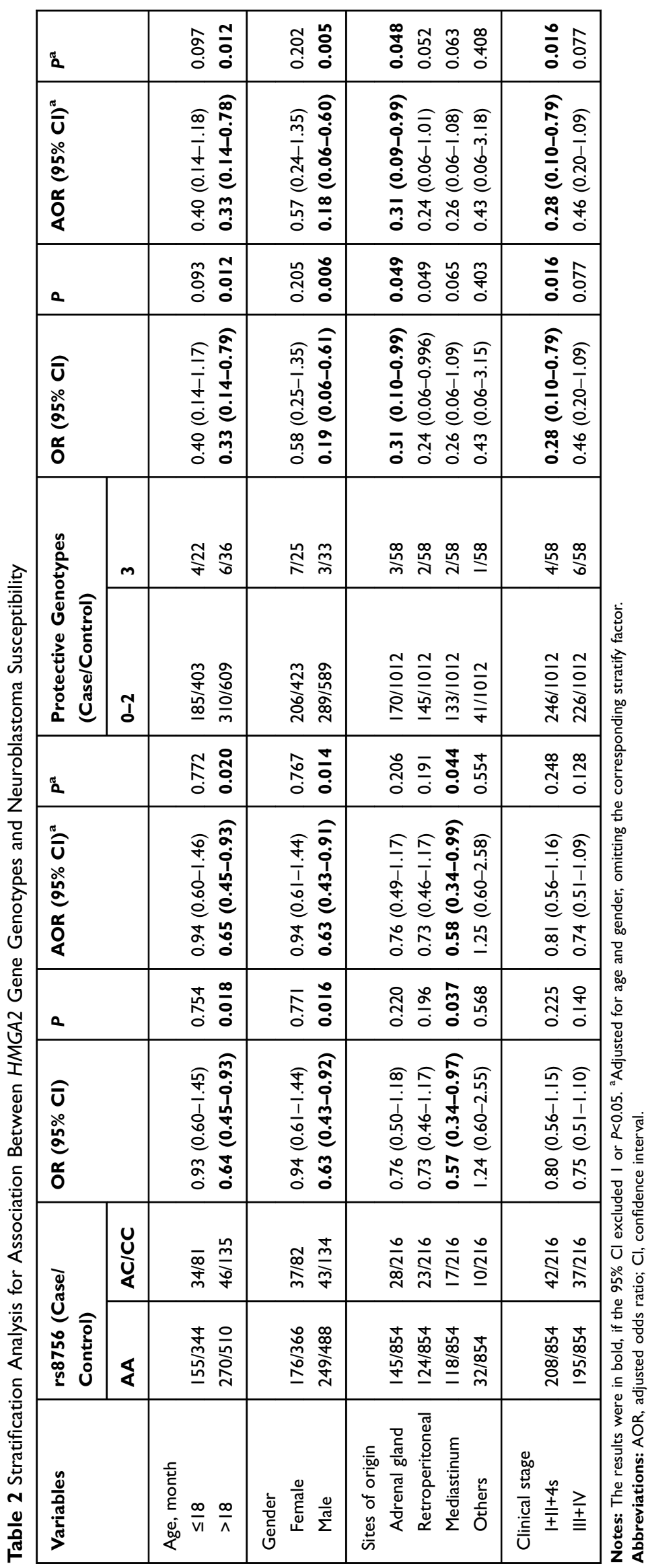


Table 3 The Frequency of Inferred Haplotypes of HMGA2 Gene Based on Observed Genotypes and Their Association with the Neuroblastoma Susceptibility

\begin{tabular}{|c|c|c|c|c|c|c|}
\hline Haplotypes $^{\mathbf{a}}$ & Cases $(n=1010)$ & Controls $(n=2 \mid 40)$ & Crude OR $(95 \% \mathrm{Cl})$ & $P$ & Adjusted $O R^{b}(95 \% \mathrm{Cl})$ & $P^{\mathbf{b}}$ \\
\hline GAT & $199(19.70)$ & $416(19.44)$ & 1.00 & & 1.00 & \\
\hline GAC & $6(0.59)$ & $12(0.56)$ & $1.05(0.39-2.84)$ & 0.923 & $1.06(0.39-2.86)$ & 0.911 \\
\hline GCT & $8(0.79)$ & $28(I .3 I)$ & $0.60(0.27-1.34)$ & 0.213 & $0.60(0.27-1.34)$ & 0.210 \\
\hline GCC & I $(0.10)$ & $2(0.09)$ & $1.05(0.10-11.65)$ & 0.968 & $1.07(0.10-11.92)$ & 0.954 \\
\hline AAT & $615(60.89)$ & $1263(59.02)$ & $1.02(0.84-1.24)$ & 0.820 & $1.02(0.84-1.24)$ & 0.824 \\
\hline AAC & $106(10.50)$ & $220(10.28)$ & $1.01(0.76-1.35)$ & 0.935 & $1.01(0.76-1.35)$ & 0.927 \\
\hline ACT & $65(6.44)$ & $|4|$ (6.59) & $0.97(0.69-1.36)$ & 0.852 & $0.97(0.69-1.36)$ & 0.849 \\
\hline $\mathrm{ACC}$ & $10(0.99)$ & $58(2.7 I)$ & $0.36(0.18-0.72)$ & 0.004 & $0.36(0.18-0.72)$ & 0.004 \\
\hline
\end{tabular}

Notes: The results were in bold, if the $95 \% \mathrm{Cl}$ excluded I or $\mathrm{P}<0.05{ }^{\mathrm{a}}{ }^{\mathrm{T}}$ The haplotypes order were rs $658 \mathrm{I} 658$, rs 8756 and rs $968697 .{ }^{\mathrm{b}}$ Obtained in logistic regression models with adjustment for age and gender.

Abbreviations: $\mathrm{OR}$, odds ratio; $\mathrm{Cl}$, confidence interval.

in vivo cardiogenesis in embryos of the frog Xenopus laevis. ${ }^{48}$ Dong et al proved that the interaction between $H M G A 2$ and $\mathrm{pRb}$ facilitated the transcriptional activation of FOXL2 by E2F1, which exert critical effects on the metastases and EMT of chemo-resistant gastric cancer. ${ }^{49}$ Further studies confirmed that HMGA2 could also modify the expression of $B c l-2$, EMT-associated proteins, and caspase activity, indicating that $H M G A 2$ plays a direct role in regulating cell apoptosis and EMT. ${ }^{50}$

Here, our research data showed that $\mathrm{rs} 8756 \mathrm{~A}>\mathrm{C}$, one SNP located at $3^{\prime}$ untranslated region (UTR) of the $H M G A 2$ gene, was related to the reduced susceptibility of neuroblastoma. It should be noted that $H M G A 2$ is a functional target of several microRNAs, which target the 3 'UTR of genes for degradation. Yu et al found that miRNA let-7 could reduce breast carcinoma cells proliferation and self-renewal partly by posttranscriptional regulation of $H M G A 2 .{ }^{51}$ And one research performed by Kang et al indicated miR-490-3p could act on the $3^{\prime}$ UTR of HMGA2 and inhibit its expression, then inhibit the proliferation, invasion, migration, and EMT of esophageal squamous cell carcinoma cells. ${ }^{52}$ A recent study confirmed that $m i R-495$ could be directly associated with the 3' UTR of HMGA2. Upregulated expression of miR-495 significantly downregulated the mRNA and protein expression levels of HMGA2 in A549 cells, and then suppressed the proliferation of lung cancer cells. ${ }^{53}$ These above studies all indicated that miRNA is an important regulatory mechanism for the expression of $H M G A 2$. It is reasonable to speculate that the $\mathrm{rs} 8756 \mathrm{~A}>\mathrm{C}$ in the $3^{\prime}$ UTR of the HMGA2 gene may affect some miRNA's binding to $H M G A 2$, thereby alternating gene expression level.

This was the first research to investigate the association between SNPs in the HMGA2 gene and neuroblastoma susceptibility. However, the relationship between $H M G A 2$ polymorphisms and other complex human diseases has been explored, such as nanism. Bouatia-Naji et al showed that rs1042725 in the $3^{\prime}$ UTR of the HMGA2 gene contributed to height variability in European populations. ${ }^{54}$ Kuipers et al further demonstrated that $H M G A 2$ polymorphism rs 1042725 may be involved in bone metabolism; A novel association between rs1042725 and trabecular bone mineral density in ethnically diverse older men was suggested. ${ }^{40}$ Further study by Hendriks et al indicated that rs1042725 is not only associated with height variation in the general population but also plays an important role in one of the extremes of the height distribution. ${ }^{55}$ Alkayyali et al found HMGA2 rs1531343 polymorphism was associated with increased risk of developing nephropathy in patients with type 2 diabetes. ${ }^{41}$ Moreover, another $3^{\prime}$ UTR polymorphism in HMGA2, rs8756 was shown to be associated with human stature in an Icelandic population. ${ }^{56}$ Our results showed that rs8756 $\mathrm{A}>\mathrm{C}$ polymorphism was associated with neuroblastoma susceptibility. The rs8756 C allele exerted protective effects against neuroblastoma. However, the other two SNPs rs6581658 $\mathrm{A}>\mathrm{G}$ and $\mathrm{rs968697} \mathrm{T}>\mathrm{C}$ were not associated with neuroblastoma risk. These results should be further validated by the well-designed studies with larger sample size.

Limitations of the current study should be notified. First, selection bias is inevitable as it is a hospital-based case-control study. Second, even we enrolled participants from four independent hospitals, the sample size is still relatively small, especially for the stratified analysis. The statistical power might be compromised. Third, only three SNPs in the HMGA2 gene were investigated; more potentially functional polymorphisms in the $H M G A 2$ gene should be assessed in the future study. Fourth, impacts of 
some environmental factors such as living environment, dietary intake, and childhood or parental exposure should be taken into account, as neuroblastoma is a heterogeneous disease with complex etiology. Such information was not available due to the nature of the retrospective investigation. Fifth, the conclusions obtained from this study may not be directly applied to other ethnicities, as only Chinese Han ethnicity was included in this study. In the last, functional experiments should be performed to further elucidate the role of $H M G A 2$ gene polymorphisms and the underlying mechanisms in neuroblastoma carcinogenesis.

\section{Conclusions}

In summary, we firstly provide evidence that polymorphism in the $H M G A 2$ gene could affect neuroblastoma risk. The $H M G A 2$ rs8756 AC/CC genotypes are associated with decreased neuroblastoma susceptibility. It suggests that $H M G A 2$ gene polymorphisms might be potential biomarkers for neuroblastoma susceptibility.

\section{Acknowledgments}

This study was supported by grants from the Pearl River S\&T Nova Program of Guangzhou (No: 201710010086) and Guangdong Provincial Key Laboratory of Research in Structural Birth Defect Disease (No: 2019B030301004), and National Natural Science Foundation of China (No: 81602666). The funder had no role in study design, data collection and analysis, decision to publish, or preparation of the manuscript.

\section{Disclosure}

The authors report no conflicts of interest in this work.

\section{References}

1. Capasso M, Diskin SJ. Genetics and genomics of neuroblastoma. Cancer Treat Res. 2010;155:65-84.

2. Gurney JG, Ross JA, Wall DA, Bleyer WA, Severson RK, Robison LL. Infant cancer in the U.S.: histology-specific incidence and trends, 1973 to 1992. J Pediatr Hematol Oncol. 1997;19 (5):428-432. doi:10.1097/00043426-199709000-00004

3. Bao PP, Li K, Wu CX, et al. [Recent incidences and trends of childhood malignant solid tumors in Shanghai, 2002-2010]. Zhonghua Er Ke Za Zhi. 2013;51(4):288-294.

4. He J, Xia H. [Experiences and dilemmas of multi-center studies on neuroblastoma]. J Clin Pediatr Surg. 2019;18(1):9-12.

5. Smith MA, Seibel NL, Altekruse SF, et al. Outcomes for children and adolescents with cancer: challenges for the twenty-first century. $J$ Clin Oncol. 2010;28(15):2625-2634. doi:10.1200/JCO.2009.27.0421

6. Delgado DC, Hank JA, Kolesar J, et al. Genotypes of NK cell KIR receptors, their ligands, and Fcgamma receptors in the response of neuroblastoma patients to Hu14.18-IL2 immunotherapy. Cancer Res. 2010;70(23):9554-9561. doi:10.1158/0008-5472.CAN-10-2211
7. Hero B, Simon T, Spitz R, et al. Localized infant neuroblastomas often show spontaneous regression: results of the prospective trials NB95-S and NB97. J Clin Oncol. 2008;26(9):1504-1510. doi:10.12 00/JCO.2007.12.3349

8. Matthay KK, Reynolds CP, Seeger RC, et al. Long-term results for children with high-risk neuroblastoma treated on a randomized trial of myeloablative therapy followed by 13-cis-retinoic acid: a children's oncology group study. J Clin Oncol. 2009;27(7):10 07-1013. doi:10.1200/JCO.2007.13.8925

9. Laverdiere C, Liu Q, Yasui Y, et al. Long-term outcomes in survivors of neuroblastoma: a report from the childhood cancer survivor study. $J$ Natl Cancer Inst. 2009;101(16):1131-1140. doi:10.1093/jnci/ djp230

10. Kaatsch P. Epidemiology of childhood cancer. Cancer Treat Rev. 2010;36(4):277-285. doi:10.1016/j.ctrv.2010.02.003

11. Maris JM, Hogarty MD, Bagatell R, Cohn SL. Neuroblastoma. Lancet. 2007;369(9579):2106-2120. doi:10.1016/S0140-6736(07)60 983-0

12. Bourdeaut F, Trochet D, Janoueix-Lerosey I, et al. Germline mutations of the paired-like homeobox 2B (PHOX2B) gene in neuroblastoma. Cancer Lett. 2005;228(1-2):51-58. doi:10.1016/j. canlet.2005.01.055

13. Mosse YP, Laudenslager M, Longo L, et al. Identification of ALK as a major familial neuroblastoma predisposition gene. Nature. 2008; 455(7215):930-935. doi:10.1038/nature07261

14. De Roos AJ, Olshan AF, Teschke K, et al. Parental occupational exposures to chemicals and incidence of neuroblastoma in offspring. Am J Epidemiol. 2001;154(2):106-114.

15. De Roos AJ, Teschke K, Savitz DA, et al. Parental occupational exposures to electromagnetic fields and radiation and the incidence of neuroblastoma in offspring. Epidemiology. 2001;12(5):508-517. doi:10.1097/00001648-200109000-00008

16. Patton T, Olshan AF, Neglia JP, Castleberry RP, Smith J. Parental exposure to medical radiation and neuroblastoma in offspring. Paediatr Perinat Epidemiol. 2004;18(3):178-185. doi:10.1111/ppe. 2004.18.issue-3

17. Han W, Zhou Y, Zhong R, et al. Functional polymorphisms in FAS/ FASL system increase the risk of neuroblastoma in Chinese population. PLoS One. 2013;8(8):e71656. doi:10.1371/journal.pone.0071656

18. Capasso M, Diskin S, Cimmino F, et al. Common genetic variants in NEFL influence gene expression and neuroblastoma risk. Cancer Res. 2014;74(23):6913-6924. doi:10.1158/0008-5472. CAN-14-0431

19. Oldridge DA, Wood AC, Weichert-Leahey N, et al. Genetic predisposition to neuroblastoma mediated by a LMO1 super-enhancer polymorphism. Nature. 2015;528(7582):418-421. doi:10.1038/nature 15540

20. Stadler ZK, Vijai J, Thom P, et al. Genome-wide association studies of cancer predisposition. Hematol Oncol Clin North Am. 2010;24 (5):973-996. doi:10.1016/j.hoc.2010.06.009

21. Maris JM, Mosse YP, Bradfield JP, et al. Chromosome 6p22 locus associated with clinically aggressive neuroblastoma. $N$ Engl J Med. 2008;358(24):2585-2593. doi:10.1056/NEJMoa0708698

22. Capasso M, Devoto M, Hou C, et al. Common variations in BARD1 influence susceptibility to high-risk neuroblastoma. Nat Genet. 2009;41(6):718-723. doi:10.1038/ng.374

23. Nguyen le B, Diskin SJ, Capasso M, et al. Phenotype restricted genome-wide association study using a gene-centric approach identifies three low-risk neuroblastoma susceptibility Loci. PLoS Genet. 2011;7(3):e1002026. doi:10.1371/journal.pgen.1002026

24. Wang K, Diskin SJ, Zhang H, et al. Integrative genomics identifies LMO1 as a neuroblastoma oncogene. Nature. 2011;469(7329):21 6-220. doi:10.1038/nature09609

25. Diskin SJ, Capasso M, Schnepp RW, et al. Common variation at $6 \mathrm{q} 16$ within HACE1 and LIN28B influences susceptibility to neuroblastoma. Nat Genet. 2012;44(10):1126-1130. doi:10.1038/ng.2387 
26. McDaniel LD, Conkrite KL, Chang X, et al. Common variants upstream of MLF1 at 3q25 and within CPZ at 4p16 associated with neuroblastoma. PLoS Genet. 2017;13(5):e1006787. doi:10.1371/journal.pgen.1006787

27. Cimmino F, Avitabile M, Diskin SJ, et al. Fine mapping of 2q35 high-risk neuroblastoma locus reveals independent functional risk variants and suggests full-length BARD1 as tumor-suppressor. Int J Cancer. 2018;143(11):2828-2837. doi:10.1002/ijc.v143.11

28. Capasso M, McDaniel LD, Cimmino F, et al. The functional variant rs34330 of CDKN1B is associated with risk of neuroblastoma. $J$ Cell Mol Med. 2017;21(12):3224-3230. doi:10.1111/jcmm.2017.21.issue-12

29. Lee JY, Kong G. Roles and epigenetic regulation of epithelial-mesenchymal transition and its transcription factors in cancer initiation and progression. Cell Mol Life Sci. 2016;73 (24):4643-4660. doi:10.1007/s00018-016-2313-Z

30. Shang Y, Cai X, Fan D. Roles of epithelial-mesenchymal transition in cancer drug resistance. Curr Cancer Drug Targets. 2013;13 (9):915-929. doi:10.2174/15680096113136660097

31. Wu J, Liu Z, Shao C, et al. HMGA2 overexpression-induced ovarian surface epithelial transformation is mediated through regulation of EMT genes. Cancer Res. 2011;71(2):349-359. doi:10.1158/0008-5472.CAN$10-2550$

32. Li Y, Zhao Z, Xu C, Zhou Z, Zhu Z, You T. HMGA2 induces transcription factor Slug expression to promote epithelial-tomesenchymal transition and contributes to colon cancer progression. Cancer Lett. 2014;355(1):130-140. doi:10.1016/j.canlet.2014.09.007

33. Hammond SM, Sharpless NE. HMGA2, microRNAs, and stem cell aging. Cell. 2008;135(6):1013-1016. doi:10.1016/j.cell.2008.11.026

34. Pfannkuche K, Summer H, Li O, Hescheler J, Droge P. The high mobility group protein HMGA2: a co-regulator of chromatin structure and pluripotency in stem cells? Stem Cell Rev. 2009;5 (3):224-230. doi:10.1007/s12015-009-9078-9

35. Fedele M, Visone R, De Martino I, et al. HMGA2 induces pituitary tumorigenesis by enhancing E2F1 activity. Cancer Cell. 2006;9 (6):459-471. doi:10.1016/j.ccr.2006.04.024

36. Sarhadi VK, Wikman H, Salmenkivi K, et al. Increased expression of high mobility group A proteins in lung cancer. J Pathol. 2006;209 (2):206-212. doi:10.1002/(ISSN)1096-9896

37. Dangi-Garimella S, Krantz SB, Barron MR, et al. Three-dimensional collagen I promotes gemcitabine resistance in pancreatic cancer through MT1-MMP-mediated expression of HMGA2. Cancer Res. 2011;71(3):1019-1028. doi:10.1158/0008-5472.CAN-10-1855

38. Wang X, Liu X, Li AY, et al. Overexpression of HMGA2 promotes metastasis and impacts survival of colorectal cancers. Clin Cancer Res. 2011;17(8):2570-2580. doi:10.1158/1078-0432.CCR-10-2542

39. Weedon MN, Lettre G, Freathy RM, et al. A common variant of HMGA2 is associated with adult and childhood height in the general population. Nat Genet. 2007;39(10):1245-1250. doi:10.1038/ng2121

40. Kuipers A, Zhang Y, Cauley JA, et al. Association of a high mobility group gene (HMGA2) variant with bone mineral density. Bone. 2009;45(2):295-300. doi:10.1016/j.bone.2009.04.197

41. Alkayyali S, Lajer M, Deshmukh H, et al. Common variant in the HMGA2 gene increases susceptibility to nephropathy in patients with type 2 diabetes. Diabetologia. 2013;56(2):323-329. doi:10.1007/ s00125-012-2760-5

OncoTargets and Therapy

\section{Publish your work in this journal}

OncoTargets and Therapy is an international, peer-reviewed, open access journal focusing on the pathological basis of all cancers, potential targets for therapy and treatment protocols employed to improve the management of cancer patients. The journal also focuses on the impact of management programs and new therapeutic

Submit your manuscript here: https://www.dovepress.com/oncotargets-and-therapy-journal
42. Cheng J, Zhuo Z, Xin Y, et al. Relevance of XPD polymorphisms to neuroblastoma risk in Chinese children: a four-center case-control study. Aging (Albany NY). 2018;10(8):1989-2000. doi:10.18632/aging. 101522

43. He J, Wang F, Zhu J, et al. Association of potentially functional variants in the XPG gene with neuroblastoma risk in a Chinese population. J Cell Mol Med. 2016;20(8):1481-1490. doi:10.1111/ jcmm.2016.20.issue-8

44. He J, Qiu LX, Wang MY, et al. Polymorphisms in the XPG gene and risk of gastric cancer in Chinese populations. Hum Genet. 2012;131 (7):1235-1244. doi:10.1007/s00439-012-1152-8

45. Chen X, Wang Y, Chen X, et al. Genetic variants in the regulatory region of SLC10A1 are not associated with the risk of hepatitis B virus infection and clearance. Infect Genet Evol. 2016;44:495-500. doi:10.1016/j. meegid.2016.07.043

46. Chang J, Zhong R, Tian J, et al. Exome-wide analyses identify low-frequency variant in CYP26B1 and additional coding variants associated with esophageal squamous cell carcinoma. Nat Genet. 2018;50(3):338-343. doi:10.1038/s41588-018-0045-8

47. Reeves R. Molecular biology of HMGA proteins: hubs of nuclear function. Gene. 2001;277(1-2):63-81. doi:10.1016/S0378-1119(01) 00689-8

48. Monzen K, Ito Y, Naito AT, et al. A crucial role of a high mobility group protein HMGA2 in cardiogenesis. Nat Cell Biol. 2008;10 (5):567-574. doi:10.1038/ncb1719

49. Dong J, Wang R, Ren G, et al. HMGA2-FOXL2 axis regulates metastases and epithelial-to-mesenchymal transition of chemoresistant gastric cancer. Clin Cancer Res. 2017;23(13):3461-3473. doi:10.1158/1078-0432.CCR-16-2180

50. Gao X, Dai M, Li Q, Wang Z, Lu Y, Song Z. HMGA2 regulates lung cancer proliferation and metastasis. Thorac Cancer. 2017;8 (5):501-510. doi:10.1111/tca.2017.8.issue-5

51. Yu F, Yao H, Zhu P, et al. let-7 regulates self renewal and tumorigenicity of breast cancer cells. Cell. 2007;131(6):1109-1123. doi:10. 1016/j.cell.2007.10.054

52. Kang NN, Ge SL, Zhang RQ, Huang YL, Liu SD, Wu KM. MiR490-3p inhibited the proliferation and metastasis of esophageal squamous cell carcinoma by targeting HMGA2. Eur Rev Med Pharmacol Sci. 2018;22(23):8298-8305. doi:10.26355/eurrev_201812_16527

53. Sun J, Qiao Y, Song T, Wang H. MiR495 suppresses cell proliferation by directly targeting HMGA2 in lung cancer. Mol Med Rep. 2019;19 (3):1463-1470. doi: $10.3892 / \mathrm{mmr} .2018 .9773$

54. Bouatia-Naji N, Marchand M, Cavalcanti-Proenca C, et al. Smallness for gestational age interacts with high mobility group A2 gene genetic variation to modulate height. Eur J Endocrinol. 2009;160 (4):557-560. doi:10.1530/EJE-08-0794

55. Hendriks AE, Brown MR, Boot AM, Oostra BA, Drop SL, Parks JS. Genetic variation in candidate genes like the HMGA2 gene in the extremely tall. Horm Res Paediatr. 2011;76(5):307-313. doi:10.1159/ 000330764

56. Gudbjartsson DF, Walters GB, Thorleifsson G, et al. Many sequence variants affecting diversity of adult human height. Nat Genet. 2008;40(5):609-615. doi:10.1038/ng.122 agents and protocols on patient perspectives such as quality of life, adherence and satisfaction. The manuscript management system is completely online and includes a very quick and fair peer-review system, which is all easy to use. Visit http://www.dovepress.com/ testimonials.php to read real quotes from published authors. 